\title{
Respiratory manifestations of eosinophilic granulomatosis with polyangiitis (Churg-Strauss)
}

\author{
Vincent Cottin (1) ${ }^{1}$, Elisabeth Bel ${ }^{2}$, Paolo Bottero ${ }^{3}$, Klaus Dalhoff ${ }^{4}$, \\ Marc Humbert $\mathbb{1}^{5}$, Romain Lazor ${ }^{6}$, Renato A. Sinico ${ }^{7}$, Pasupathy Sivasothy ${ }^{8}$, \\ Michael E. Wechsler ${ }^{9,10}$, Matthieu Groh ${ }^{11}$, Sylvain Marchand-Adam ${ }^{12}$, \\ Chahéra Khouatra ${ }^{1}$, Benoit Wallaert ${ }^{13}$, Camille Taillé ${ }^{14}$, Philippe Delaval ${ }^{15}$, \\ Jacques Cadranel ${ }^{16}$, Philippe Bonniaud ${ }^{17}$, Grégoire Prévot $^{18}$, Sandrine Hirschi ${ }^{19}$, \\ Anne Gondouin ${ }^{20}$, Bertrand Dunogué ${ }^{10}$, Gérard Chatté ${ }^{21}$, Amandine Briault ${ }^{22}$, \\ David Jayne ${ }^{23}$, Loïc Guillevin ${ }^{24}$, Jean-François Cordier ${ }^{1}$ and the Groupe d'Etudes \\ et de Recherche sur les Maladies Orphelines Pulmonaires (GERM“O”P) ${ }^{25}$
}

ABSTRACT The respiratory manifestations of eosinophilic granulomatosis with polyangiitis (EGPA) have not been studied in detail.

In this retrospective multicentre study, EGPA was defined by asthma, eosinophilia and at least one new onset extra-bronchopulmonary organ manifestation of disease.

The study population included 157 patients (mean \pm SD age $49.4 \pm 14.1$ years), with a mean \pm SD blood eosinophil count of $7.4 \pm 6.4 \times 10^{9} \mathrm{~L}^{-1}$ at diagnosis. There was a mean $\pm \mathrm{SD}$ of $11.8 \pm 18.2$ years from the onset of asthma to the diagnosis of EGPA, of $1.4 \pm 8.4$ years from the first onset of peripheral eosinophilia to the diagnosis of EGPA, and of 7.4 \pm 6.4 years from EGPA diagnosis to the final visit. Despite inhaled and oral corticosteroid treatment, the severity of asthma increased 3-6 months before the onset of the systemic manifestations. Asthma was severe in $57 \%, 48 \%$, and $56 \%$ of patients at diagnosis, at 3 years, and at the final visit, respectively. Persistent airflow obstruction was present in $38 \%, 30 \%$, and $46 \%$ at diagnosis, at 3 years, and at the final visit, respectively.

In EGPA, asthma is severe, antedates systemic manifestations by a mean of 12 years, and progresses to long-term persistent airflow obstruction despite corticosteroids in a large proportion of patients, which affects long-term management and morbidity.

@ERSpublications

In EGPA, asthma is severe and progresses to persistent airflow obstruction despite corticosteroids in many patients http://ow.ly/8uf8301KSoT

Received: Jan 132016 | Accepted after revision: June 012016 | First published online: Sept 12016

Conflict of interest: Disclosures can be found alongside this article at erj.ersjournals.com

Copyright @ERS 2016 
Affiliations: ${ }^{1}$ Hospices civils de Lyon, Hôpital Louis Pradel, Service de pneumologie - centre de référence des maladies orphelines pulmonaires; Université de Lyon, Université Lyon I; UCBL-INRA-ENVL-EPHE, UMR754; IFR128; Lyon, France. ${ }^{2}$ Dept of Respiratory Medicine, Academic Medical Center, Amsterdam, The Netherlands. ${ }^{3}$ Allergy and Clinical Immunology Outpatient Clinic, Ospedale "G. Fornaroli" di Magenta, Azienda Ospedaliera di Legnano, Milan, Italy. ${ }^{4}$ Medical University of Lübeck, Dept of Internal Medicine, Lübeck, Germany. ${ }^{5} \mathrm{CHU}$ Bicêtre, service de pneumologie, Le Kremlin-Bicêtre, France. ${ }^{6}$ Interstitial and rare lung disease unit, Respiratory Medicine Dept, University Hospital, Lausanne, Switzerland. ${ }^{7}$ Dept of Medicine, Clinical Immunology Unit, Azienda Ospedaliera Ospedale San Carlo Borromeo, Milan, Italy. ${ }^{8}$ Dept of Respiratory Medicine, Addenbrookes Hospital, Cambridge University Hospitals Foundation Trust, Cambridge, UK. ${ }^{9}$ National Jewish Health, Denver, CO, USA. ${ }^{10}$ University of Colorado, Aurora, CO, USA. ${ }^{11}$ Dept of Internal Medicine, National Referral Center for Rare Autoimmune and Systemic Diseases, Hôpital Cochin, Assistance Publique Hôpitaux de Paris, Université Paris Descartes, Paris, France. ${ }^{12} \mathrm{CHRU}$ Tours, service de pneumologie et université Francois Rabelais Tours, Tours, France. ${ }^{13} \mathrm{CHRU}$ Lille, service de pneumologie, Lille, France. ${ }^{14}$ INSERM U1152; Univ Paris Diderot, Sorbonne Paris Cité; Assistance Publique - Hôpitaux de Paris, Hôpital Bichat, Service de Pneumologie A; Département hospitalo-universitaire FIRE, Competence Center for Rare Pulmonary Diseases, Paris, France. ${ }^{15} \mathrm{CHU}$ Rennes, service de pneumologie, Rennes, France. ${ }^{16} \mathrm{Chest}$ Dept and Expert Center for Rare Pulmonary Diseases, APHP Hôpital Tenon and P\&M Curie University Paris 6, Paris, France. ${ }^{17}$ Service de Pneumologie et Soins Intensifs Respiratoires, Centre Hospitalier universitaire (CHU) François Mitterrand, Inserm U866, Université de Bourgogne, Faculté de Médecine et Pharmacie, Dijon, France. ${ }^{18} \mathrm{CHU}$ de Toulouse, service de pneumologie, Toulouse, France. ${ }^{19} \mathrm{CHU}$ de Strasbourg, service de pneumologie, Strasbourg, France. ${ }^{20} \mathrm{CHU}$ de Besançon, service de pneumologie, Besançon, France. ${ }^{21}$ Centre de Pneumologie et Allergologie Respiratoire, Caluire et Cuire, France. ${ }^{22} \mathrm{CHU}$ de Grenoble, service de pneumologie, Grenoble, France. ${ }^{23}$ Dept of Medicine, University of Cambridge, UK. ${ }^{24} \mathrm{AP}-\mathrm{HP}$, hôpital Cochin, université Paris-Descartes, Sorbonne Paris Cité, service de médecine interne, Inserm 1016, Paris, France. ${ }^{25} \mathrm{~A}$ full list of the Groupe d'Etudes et de Recherche sur les Maladies Orphelines Pulmonaires (GERM“O"P) members and their affiliations can be found in the Acknowledgements section.

Correspondence: Vincent Cottin, National reference center for rare pulmonary diseases, Hôpital Louis Pradel, F-69677 Lyon Cedex, France. E-mail: vincent.cottindachu-lyon.fr

\section{Introduction}

Eosinophilic granulomatosis with polyangiitis (EGPA) (previously known as Churg-Strauss syndrome) is defined as an eosinophil-rich and necrotising granulomatous inflammation often involving the respiratory tract, with necrotising vasculitis predominantly affecting small to medium vessels, and associated with asthma and eosinophilia [1]. The nomenclature of the systemic vasculitides was revised in 2012 at the international Chapel Hill consensus conference [1], and the terminology of Churg-Strauss syndrome was replaced by EGPA [2]. The classical description of EGPA follows three stages [3, 4]: 1) asthma and rhinitis; 2) tissue eosinophilia (including eosinophilic pneumonia); and 3) extra-pulmonary eosinophilic disease with vasculitis.

Although asthma is a key component of the definition and a classification criterion for EGPA [1, 5], few studies have evaluated specifically the respiratory manifestations of EGPA, especially the respective chronology and severity of asthma and of the systemic vasculitis, and the outcome in terms of asthma and lung function with treatment of the vasculitis. Asthma in EGPA is classically severe [6] and corticosteroid dependent [7], and precedes the onset of the systemic disease by several years [8]. The severity of asthma is thought to attenuate with the onset of the vasculitis [7]. A majority of patients may require long-term maintenance treatment with low-dose oral corticosteroids to control asthma once remission of the systemic eosinophilic disease has been obtained [8]. We have previously shown in a single centre series of 24 consecutive patients that persistent airflow obstruction due to uncontrolled asthma is present despite oral corticosteroids in many patients at diagnosis, at clinical remission of EGPA and during follow-up, with the possibility of partial reversibility in some cases upon transient increase of oral corticosteroid dose [9].

Here, we describe bronchopulmonary manifestations in a retrospective multicentre analysis of 157 patients with EGPA, and clarify the severity of asthma and timelines of change with regard to treatment.

\section{Patients and methods}

\section{Study design and data collection}

This retrospective study was undertaken by the Groupe d'Etudes et de Recherche sur les Maladies Orphelines Pulmonaires (GERM“O”P), a French group dedicated to the study of rare (so-called orphan) pulmonary diseases, including EGPA, and by members of a European Respiratory Society task force on EGPA. A detailed questionnaire was sent to physicians who previously had prospectively reported cases of EGPA to the GERM"O"P registry and to members of the task force who had prospectively collected data in their own databases. Questionnaires were filled in by reviewing medical records. A standard form was used to systematically collect data including epidemiological characteristics, smoking history, atopic status, clinical manifestations, imaging, and medications from the medical files, both at diagnosis and during outcome, with a special focus on respiratory manifestations. The study was approved by the Institutional 
Review Board of the Société de Pneumologie de Langue Française (Paris, France). The database was anonymous and complied with the requirements of the Commission Nationale Informatique et Libertés. Patients received information attesting their unrestricted rights to ask for the deletion of their data from the database.

\section{Patient selection}

The diagnosis of EGPA was reassessed by the investigators, and cases were included if they met the following inclusion criteria, derived from those proposed by Lanham et al. [7] and modified as follows: 1) asthma; 2) eosinophilia defined by blood eosinophilia $>1.5 \times 10^{9} \mathrm{~L}^{-1}$ on at least one measurement, and/or blood eosinophilia $>10 \%$ of leukocytes, and/or marked biopsy-proven tissue eosinophilia along with blood eosinophilia $>0.75 \times 10^{9} \mathrm{~L}^{-1}$; and 3) at least one new onset extra-bronchopulmonary organ manifestation of disease (other than rhinosinusitis or other ear, nose and throat (ENT) manifestations). Data from the entire follow-up period were taken into account [10], and patients who were eventually diagnosed as having other eosinophilic lung disorders were excluded. Patients with a single systemic manifestation confidently attributable to the disease were included to account for the possibility of early diagnosis of disease ("formes frustes" of EGPA).

\section{Treatment}

Treatment was left to the discretion of the physician and followed standard of care guidelines. In addition to corticosteroid treatment, oral or intravenous cyclophosphamide was used as induction therapy in patients with factors associated with a poor prognosis [11], followed by maintenance therapy using immunosuppressive therapy after complete clinical remission of the systemic disease was obtained. Azathioprine or methotrexate was used in patients in whom the corticosteroids could not be tapered below $20 \mathrm{mg} \cdot \mathrm{day}^{-1}$ of prednisone.

\section{Classification of organ manifestations}

Systemic organ manifestations considered direct definite manifestations of vasculitis included biopsy-proven necrotising vasculitis of any organ, necrotising glomerulonephritis or crescentic glomerulonephritis (biopsy proven), alveolar haemorrhage (defined as bloody bronchoalveolar lavage return with compatible opacities on chest radiogrpahy and/or high-resolution computed tomography (CT)), palpable purpura, or myocardial infarction due to proven coronary arteritis (related to the systemic disease, e.g. non-atheromatous coronary stenosis at coronarography or myocardial infarction without coronary atherosclerosis).

In addition, strong surrogates of systemic vasculitis included: 1) haematuria associated with red cell casts or $>10 \%$ dysmorphic erythrocytes, or haematuria and $2+$ proteinuria on urinalysis (related to the systemic disease, no biopsy) [12]; and 2) any organ manifestation other than ENT or bronchopulmonary manifestation associated with a biopsy demonstrating leukocytoclastic capillaritis and/or eosinophilic infiltration of the arterial wall [2]. Patients with definite manifestations of vasculitis or a strong surrogate of vasculitis were considered as having systemic vasculitis.

Other new onset systemic manifestations were considered related to EGPA when suggested by chronology and the absence of another plausible cause; however, they were not considered direct manifestations of vasculitis, and these included especially mononeuritis or mononeuritis multiplex (for the first step of analysis), or cardiomyocarditis confidently attributed to the eosinophilic disorder, pericarditis other than asymptomatic mild pericardial effusion, renal disease other than defined above, and any other organ/ system manifestation with significant eosinophilic infiltration at biopsy or convincingly related to eosinophilic disease (without biopsy).

\section{Assessments}

Fever was defined as a temperature $>38^{\circ} \mathrm{C}$. Weight loss was defined as $>5 \%$ of body weight or $>3 \mathrm{~kg}$ over the 3 months prior to the diagnosis. Heart manifestations were diagnosed based on clinical findings in combination with ultrasound and electrocardiogram results [11]. Myocarditis was defined as a patient with clinical manifestations of heart failure, decreased systolic ejection fraction, increased N-terminal pro-brain natriuretic peptide or brain natriuretic peptide, and/or increased serum troponin level. Definite respiratory allergy was defined by presence of allergy symptoms, increased specific IgE and positive prick tests consistent with the exposure and with the seasons of symptoms. Chronic rhinosinusitis was defined as presence of nasal discharge, headache, nasal obstruction and/or hyposmia, for more than 12 weeks with no complete resolution of symptoms [13].

Antineutrophil cytoplasmic antibodies (ANCA) were considered positive when detected by immunofluorescence and by ELISA in the serum at diagnosis or later during the course of disease when initially tested negative. Biopsy findings were recorded as normal or showing necrotising vasculitis, 
eosinophilic tissue infiltration, granulomas, or specific organ features (necrotising glomerulonephritis or crescentic glomerulonephritis).

Pulmonary function tests were performed with standard protocols, and following international guidelines [14]. Values were expressed as a percentage of predicted values, except for forced expiratory volume in $1 \mathrm{~s}$ (FEV1)/ forced vital capacity (FVC) which was expressed as absolute percentage. FEV1 and FEV1/FVC were assessed before bronchodilators and then 10-15 min after the administration of a short-acting inhaled beta-2-agonist. Persistent airflow obstruction was defined by a post-bronchodilator FEV1/FVC ratio $<0.70$ with $\mathrm{FEV} 1<80 \%$ of predicted [9].

Asthma severity was defined as follows. Mild: requiring low-dose inhaled corticosteroids or other low-intensity treatment (e.g. cromolyn or leukotriene receptor antagonists); moderate: requiring low- to moderate-dose inhaled corticosteroids and long-acting beta-2-agonists (or other extra treatment); severe: requiring high-intensity treatment (high-dose inhaled corticosteroids and long-acting beta-2-agonists with or without oral corticosteroids and/or other extra treatment) $[15,16]$.

Chest CT was reviewed at each institutional site by academic radiologists and pulmonologists, and data obtained by consensus were collected using a standard form. Imaging bronchopulmonary features were categorised into: 1) an airway pattern consisting of small centrilobular nodules, V-or Y-shaped opacities, tree-in-bud sign, bronchial dilatation and wall thickening, and mosaic perfusion pattern; and 2) an airspace pattern consisting of ground-glass opacities, consolidation and poorly defined nodules [17].

The prognosis five factor score and the revised five factor score were evaluated as described [11, 18]. Clinical remission was defined as the absence of clinical manifestations of the systemic disease and a peripheral eosinophil count $<1 \times 10^{9} \mathrm{~L}^{-1}$ for at least three consecutive months. A relapse of EGPA $[10,19,20]$ was defined as the recurrence or worsening of a clinical manifestation of EGPA following a period of remission of at least 3 months, and/or the need to resume corticosteroid therapy, increase the daily dose of oral or intravenous corticosteroids or initiate immunosuppressive therapy due to clinical manifestations of EGPA other than asthma or rhinosinusitis exacerbation. A relapse (exacerbation) of respiratory manifestation was defined as increase or recurrence of asthma, sinusitis or rhinitis symptoms, with or without an increase in eosinophil blood cell count and requiring therapeutic adjustment.

\section{Statistical analysis}

All results were expressed as mean \pm SD for continuous variables and number (percentage) for categorical variables, unless stated otherwise. Continuous variables were compared using the nonparametric MannWhitney test. Categorical variables were compared using the Fisher's exact test. The duration of follow-up was calculated using the Kaplan-Meier method, from the time of EGPA diagnosis to death or last follow-up visit. GraphPad Prism (GraphPad Software, Inc., La Jolla, CA, USA) and SPSS 13.0 (SPSS Inc., Chicago, IL, USA) software were used. Results were considered significant for $\mathrm{p}<0.05$.

\section{Results}

\section{Patient characteristics, diagnostic criteria and systemic manifestations}

Out of 168 case report forms received, 11 were excluded, because of the absence of extra-respiratory organ manifestation in 10 cases and the absence of eosinophilia in one case. A total of 157 cases were included (table 1), with a mean \pm SD age of $49.4 \pm 14.1$ years (range: $17.2-80.9$ years), $51 \%$ of whom were female.

According to the inclusion criteria, all patients had a history of asthma, eosinophilia and at least one systemic organ manifestation (other than asthma, pulmonary or ENT involvement) directly attributable to EGPA. All patients fulfilled previous provisional diagnostic criteria [21]; 148 (94\%) fulfilled the classification criteria established by the American College of Rheumatology [22]; the other nine patients all had at least two extra-thoracic organ manifestations attributable to the disease.

Of 157 patients with at least one systemic manifestation, $42(27 \%)$ patients had one systemic manifestation other than asthma or pulmonary or ENT involvement, 46 (29\%) had two manifestations, 34 (22\%) had three manifestations, 14 (9\%) had four manifestations, and 21 (13\%) had five or more systemic manifestations.

A total of 63 (40\%) patients had definite vasculitis features as defined by biopsy-proven necrotising vasculitis (28 (18\%) patients), biopsy proven necrotising glomerulonephritis or crescentic glomerulonephritis (nine (6\%) patients), leukocytoclastic capillaritis (21 (13\%) patients), alveolar haemorrhage (six (4\%) patients), palpable purpura $(26(17 \%)$ patients), or haematuria (14 (9\%) patients), myocardial infarction due to coronary arteritis (eight (5\%) patients), or biopsy-proven vasculitis of another organ (10 (6\%) patients). Among patients with definite vasculitis, 30 patients had one organ involved, 21 patients had two organs involved, eight patients had three organs involved, three patients had four organs involved, and one patient had six organs involved. 
TABLE 1 Systemic organ and vasculitic manifestations in 157 patients with eosinophilic granulomatosis with polyangiitis throughout the course of the disease

\begin{tabular}{|c|c|}
\hline Asthma & $157(100 \%)$ \\
\hline Eosinophilia"\# & $157(100 \%)$ \\
\hline \multicolumn{2}{|l|}{ General manifestations } \\
\hline Fever $>38^{\circ} \mathrm{C}$ & $62(39 \%)$ \\
\hline Weight loss ( $>5 \%$ or $3 \mathrm{~kg}$ in the past 3 months) & $73(46 \%)$ \\
\hline Myalgia & $60(38 \%)$ \\
\hline Polyarthralgias & $39(25 \%)$ \\
\hline \multicolumn{2}{|l|}{ Cardiac and vascular manifestations } \\
\hline Myocarditis & $49(31 \%)$ \\
\hline Patent ${ }^{\Uparrow}$ & $36(23 \%)$ \\
\hline Latent $^{+}$ & $12(8 \%)$ \\
\hline Myocardial infarction & $1(1 \%)$ \\
\hline Arrhythmia or atrioventricular block & $12(8 \%)$ \\
\hline Pericarditis (echocardiography and/or CT) & $32(20 \%)$ \\
\hline Small effusion & $23(15 \%)$ \\
\hline Large effusion & $4(3 \%)$ \\
\hline Large effusion requiring drainage & $5(3 \%)$ \\
\hline Venous thromboembolism & $8(5 \%)$ \\
\hline \multicolumn{2}{|l|}{ Renal manifestations } \\
\hline Crescentic glomerulonephritis (biopsy proven) & $9(6 \%)$ \\
\hline $\begin{array}{l}\text { Other glomerulonephritis (focal segmental glomerulonephritis, membranous } \\
\text { glomerulonephritis) }\end{array}$ & $2(1 \%)$ \\
\hline Interstitial nephritis & 0 \\
\hline Proteinuria $>0.3 \mathrm{~g} \cdot$ day $^{-1}$ & $19(12 \%)$ \\
\hline Renal failure (creatinine $>124 \mu \mathrm{mol} \cdot \mathrm{L}^{-1}$ or $1.4 \mathrm{mg} \cdot \mathrm{dL}^{-1}$ ) & $7(4 \%)$ \\
\hline \multicolumn{2}{|l|}{ Neurological manifestations } \\
\hline Mononeuritis multiplex & $56(36 \%)$ \\
\hline Peripheral neuropathy & $43(27 \%)$ \\
\hline \multicolumn{2}{|l|}{ Cutaneous manifestations } \\
\hline Vascular purpura (palpable) & $26(17 \%)$ \\
\hline Subcutaneous nodules & $7(4 \%)$ \\
\hline Livedo & $2(1 \%)$ \\
\hline Urticaria & $13(8 \%)$ \\
\hline \multicolumn{2}{|l|}{ Gastro-intestinal manifestations } \\
\hline Abdominal pain lassociated with nausea, vomiting, diarrhoeal & $33(21 \%)$ \\
\hline Digestive haemorrhage & $4(3 \%)$ \\
\hline \multicolumn{2}{|l|}{ Other } \\
\hline Eye involvement & $2(1 \%)$ \\
\hline Urogenital & $1(1 \%)$ \\
\hline
\end{tabular}

CT: computed tomography. " : defined as peripheral blood eosinophilia $>1.5 \times 10^{9} \mathrm{~L}^{-1}$ or $10 \%$ of leukocytes; " i.e. clinical manifestations of heart failure and/or decreased systolic ejection fraction, increased N-terminal pro-brain natriuretic petide, increased troponin $\mathrm{I}^{+}{ }^{+}$isolated magnetic resonance imaging abnormalities.

A biopsy contributed to the diagnosis of EGPA in 89 (57\%) patients, demonstrating necrotising vasculitis of small-to-medium size vessels (18\%), leukocytoclastic capillaritis (13\%), eosinophilic infiltration of the arterial wall (8\%) or of the adjacent tissue (18\%), extravascular granulomas (6\%), and/or giant cells (4\%).

The mean \pm SD maximal peripheral eosinophil count was $7.4 \pm 6.4 \times 10^{9} \mathrm{~L}^{-1}$, with a mean of $1.4 \pm 8.4$ years from the first onset of peripheral eosinophilia to the diagnosis of EGPA. 41 (26\%) patients were taking a leukotriene receptor antagonist (montelukast in all cases) at the time of diagnosis. The median delay between initiation of anti-leukotriene antagonists was 0.67 years (from 21 days to 8.1 years), and the median duration of treatment with anti-leukotriene antagonists until the diagnosis of EGPA was 0.50 years (from 7 days to 2.58 years). The anti-leukotriene therapy was generally discontinued at the time of the diagnosis of EGPA.

The five factor score was 0 in 104 patients, 1 in 42 patients, and 2 in 11 patients. The revised five factor score was 0 in 90 patients, 1 in 45 patients, 2 in 20 patients, and 3 in two patients. 
ANCAs and biology

ANCAs were found at the time of diagnosis in 48 (31\%) patients, including 46 (29\%) with anti-myeloperoxidase specificity and $2(1 \%)$ with anti-proteinase 3 antibodies at ELISA. The pattern of ANCA at immunofluorescence was perinuclear in $23(15 \%)$ patients, cytoplasmic in $10(6 \%)$ and unknown in 15 (10\%). The total serum IgE level was $981 \pm 1571 \mathrm{mg} \cdot \mathrm{L}^{-1}$. The C-reactive protein serum level was $53 \pm 48 \mathrm{mg} \cdot \mathrm{L}^{-1}$.

The diagnosis of allergic bronchopulmonary aspergillosis, idiopathic hypereosinophilic syndrome, parasitic infection and drug-related eosinophilia with systemic symptoms was confidently ruled out in all cases. However, a positive IgG serology for Aspergillus fumigatus was found in 6 (4\%) patients; 4 (3\%) patients had low level peripheral blood T-cell clones and $8(5 \%)$ had monoclonal gammopathy of unknown significance.

\section{Asthma and pulmonary function tests at diagnosis}

Asthma was present in all patients and antedated the onset of the systemic manifestations by a mean \pm SD of $11.8 \pm 18.2$ years; it occurred concomitantly with the vasculitis in a single patient. The mean $\pm \mathrm{SD}$ time from first occurrence of peripheral blood eosinophilia to onset of systemic manifestations was $1.4 \pm 8.4$ years.

At the diagnosis of EGPA, 144 (92\%) patients had dyspnoea on exertion; 102 (65\%) had cough, including 40 (25\%) with sputum production; 25 (16\%) patients reported chest pain; and 11 (7\%) had haemoptysis.

$45(29 \%)$ patients had a history of tobacco smoking, including 10 (6\%) with active smoking at diagnosis, with a mean \pm SD of $20.8 \pm 22.0$ (range $1-100$ ) pack-years.

Pulmonary function tests available at diagnosis in 142 patients (90\%) demonstrated a post-bronchodilator FEV1 of $69.7 \pm 24.9 \%$ predicted, post-bronchodilator FEV1/FVC of $68.9 \pm 15.3 \%$, and post-bronchodilator FVC of $82.8 \pm 23.1 \%$ predicted. Post-bronchodilator FEV $1 / F V C$ was $<0.7$ in $54 \%$ of tested patients. Asthma severity was mild in $17 \%$ of patients, moderate in $26 \%$ of patients and severe in $57 \%$ of patients.

\section{ENT manifestations}

Three-quarters of the patients had clinical manifestations of chronic rhinosinusitis, $72 \%$ of them of non-allergic type (table 2), with presence of maxillary rhinosinusitis at CT in 66\%. About half of the patients had a history of nasal polyposis; with a complicated course requiring surgery in $55 \%$ of them and relapse of nasal polyposis occurring in $28 \%$ of cases. Chronic otitis media was less frequent; however, it caused hearing loss in $6 \%$ of the patient cohort.

\section{Allergy}

A definite history of respiratory allergy was present in 43 (27\%) patients (table 3), 21 (13\%) of them also had a family history of allergy. The most frequent allergies identified were Dermatophagoides pteronyssimus and D. farina (16\% of patients), grass (8\%), Aspergillus (6\%), cat (5\%), dog (3\%), short-ragweed (3\%), birch (2\%) and Alternaria (2\%). Only 3\% of the patients had been desensitised to Dermatophagoides.

Asthma and rhinitis symptoms were seasonal in $10 \%$ and $15 \%$ of the cases, respectively, and were perennial in the remaining cases. Four (3\%) patients had a history of vaccination within 2 months before the EGPA diagnosis. Interestingly, 33 (21\%) patients had a history of food and drug pseudoallergic reactions, involving

TABLE 2 Ear, nose and throat manifestations in 157 patients with eosinophilic granulomatosis with polyangiitis throughout the course of the disease

\begin{tabular}{lc}
\hline Clinical chronic rhinosinusitis & $114(73 \%)$ \\
Allergic type & $33(21 \%)$ \\
Non-allergic type & $81(52 \%)$ \\
Maxillary rhinosinusitis on computed tomography & $103(66 \%)$ \\
Unilateral & $10(6 \%)$ \\
Bilateral & $94(60 \%)$ \\
Nasal polyposis & $83(53 \%)$ \\
Requiring surgery & $46(29 \%)$ \\
Relapse after surgery & $23(15 \%)$ \\
Nasal crusting & $23(15 \%)$ \\
Otitis media & $22(14 \%)$ \\
Secretory otitis media & $15(10 \%)$ \\
Chronic otitis media with discharge & $7(4 \%)$ \\
Causing sensoneural hearing loss & $9(6 \%)$ \\
\end{tabular}


TABLE 3 Allergic manifestations in patients with eosinophilic granulomatosis with polyangiitis (EGPA)

$\begin{array}{lc}\text { Definite history of respiratory allergy } & 43(27 \%) \\ \text { Definite allergic asthma } & 40(25 \%) \\ \text { Definite allergic rhinitis } & 34(22 \%) \\ \quad \text { With asthma symptoms } & 113(72 \%) \\ \text { Seasonal:perennial asthma } & 7: 106 \\ \text { With rhinitis symptoms } & 96(61 \%) \\ \text { Seasonal:perennial rhinitis } & 14: 82 \\ \text { Insect venom allergy } & 0 \\ \text { Family history of allergy } & 21(13 \%) \\ \text { History of vaccination within 2 months before the EGPA diagnosis } & 4(3 \%) \\ \text { Food and drug pseudoallergic reactions } & 38(24 \%)\end{array}$

a reaction to aspirin and nonsteroidal anti-inflammatory agents (8\%), food additives (3\%) or alcohol (10\%). None of the patients was allergic to insect venom.

\section{Pulmonary imaging manifestations}

Abnormalities of the chest radiograph were present at diagnosis in 91 (58\%) patients, consisting of ground-glass attenuation in $46(29 \%)$ patients, consolidation in 45 (29\%) patients, nodules or masses in 14 (9\%) patients, and pleural effusion in $15(10 \%)$ patients. Distribution of abnormalities was bilateral in $58 \%$ of the cases.

Imaging features on CT are reported in table 4. Features were analysed as an airspace pattern in $30 \%$ of the cases, airway pattern in $15 \%$ of cases and mixed pattern in $10 \%$ of cases; the features were considered indeterminate in $45 \%$ of cases.

TABLE 4 Computed tomography (CT) features in patients with eosinophilic granulomatosis with polyangiitis at diagnosis ( $\mathrm{n}=136$ )

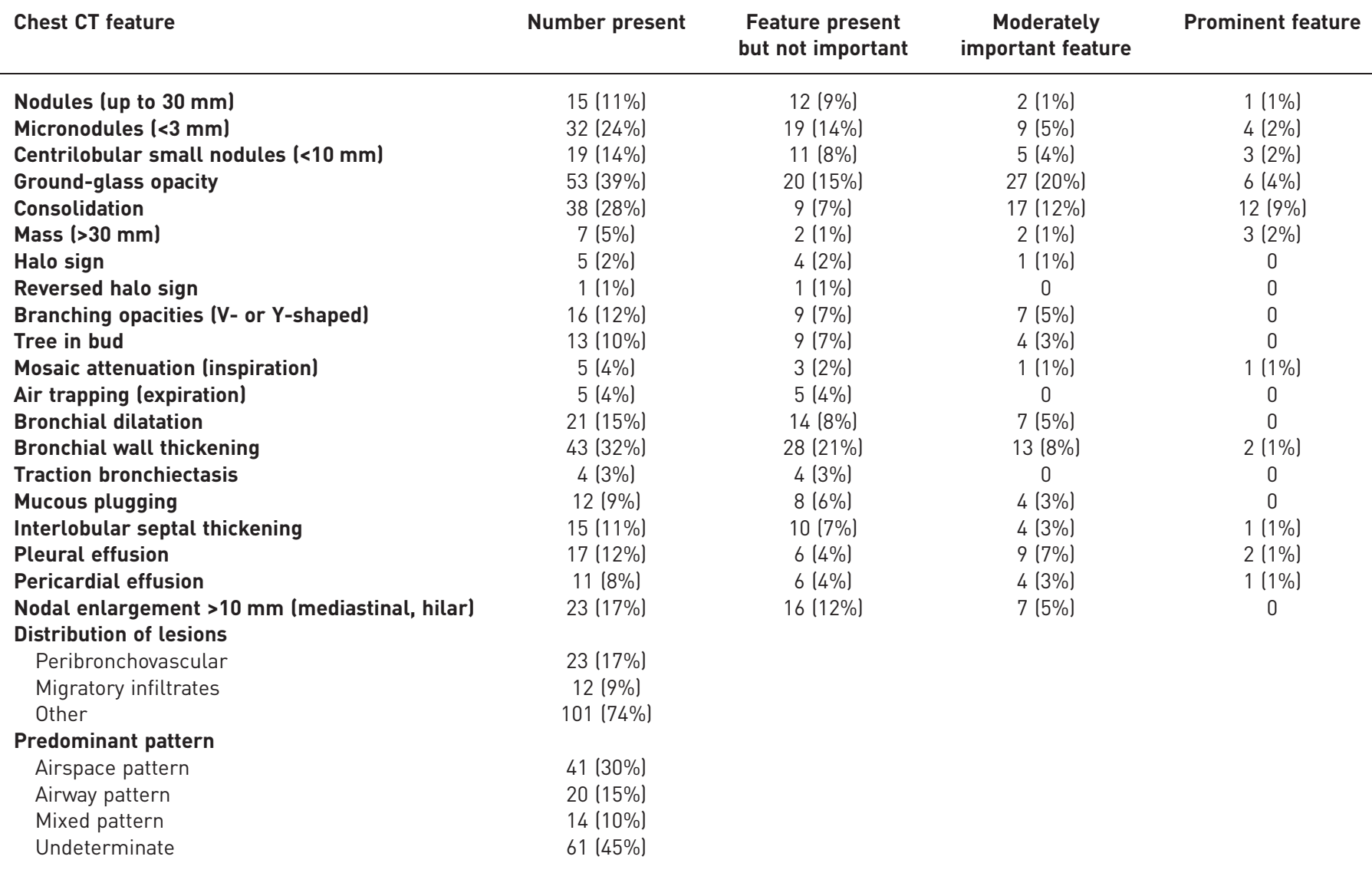




\section{Bronchoalveolar lavage}

Fibre-optic bronchoscopy was performed in 92 cases and demonstrated diffuse inflammation of the bronchial mucosa in 27 (29\%) patients, mucous secretions in 14 (15\%) patients, and whitish granulations in eight (9\%) patients. Bronchoalveolar lavage findings are shown in table 5, including a mean of $33 \%$ eosinophils at differential cell count.

\section{Pleural effusion}

Pleural effusion was related directly to EGPA by the investigator in 10 cases, and to heart failure in two cases (indeterminate cause in five cases). It was bilateral in nine out of 15 cases, corresponding to an exudate in five of six cases explored (with $20 \%$ eosinophils or more in three cases, and 50\% eosinophils or more in two cases).

\section{Asthma severity and outcome}

Although the evaluation of asthma severity was not available at each time point in all patients, the severity of asthma tended to increase 3-6 months before the onset of the systemic disease (figure 1).

All patients received a systemic corticosteroid treatment for EGPA and/or also received immunosuppressive therapy (table 6). Six (4\%) patients also received omalizumab. In addition, all patients with chronic asthma received high-dose inhaled corticosteroids and bronchodilators.

The overall follow-up for the 157 patients was 7.4 \pm 6.4 years from the diagnosis of EGPA. Three patients died (ventricular fibrillation in one case; unknown cause in two cases). 201 relapse events occurred in 71 (46\%) patients, corresponding in two-thirds of the cases to relapse of asthma symptoms generally accompanied by an increase in peripheral eosinophil cell count $>1 \times 10^{9} \mathrm{~L}^{-1}$, and relapse of the systemic disease in the remaining cases. The number of relapses did not correlate with the number of systemic features at baseline, the number of vasculitis features at baseline, or the revised five factor score (data not shown). The number of relapses did not differ between patients with a revised five factor score of 1 or greater $(2.20 \pm 2.25$ relapses $)$ and those with a score of $0(2.86 \pm 1.70$ relapses; $\mathrm{p}=0.163) .27 \%$ of patients had long-term sequelae, including $8 \%$ who had debilitating persistent chronic asthma as reported by the investigator. Most patients had steroid side-effects (not quantified).

Despite treatment, the severity of asthma remained unchanged in the subsequent months and years following the diagnosis of EGPA. As shown in figure 1, more than $80 \%$ of patients received oral

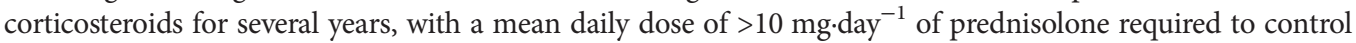
asthma. Treatment was associated with a decrease in eosinophilia, and with the mean peripheral eosinophil cell count remaining lower than $1.0 \times 10^{9} \mathrm{~L}^{-1}$ over the long-term. However, FEV1/FVC remained $<0.7$ in $25-$ $35 \%$ of patients (depending on the time point). In addition, a short course of systemic corticosteroid treatment was required in 11-18\% of patients per year, and nonelective hospital admission was required for asthma in $\sim 10 \%$ of patients each year, with no major decrease after initiation of systemic therapy (figure 1).

\section{Discussion}

In this study of respiratory manifestations in patients with EGPA we showed that asthma, which was present in all patients, antedated the onset of the systemic manifestations by a mean $\pm \mathrm{SD}$ of $11.81 \pm 18.18$ years.

TABLE 5 Bronchoalveolar lavage findings in patients with eosinophilic granulomatosis with polyangiitis

\begin{tabular}{|c|c|}
\hline $\begin{array}{l}\text { Subjects } n \\
\text { Blood eosinophils at the time of } B A L \times 10^{9} L^{-1}\end{array}$ & $\begin{array}{c}92 \\
3.8 \pm 5.2\end{array}$ \\
\hline Patients receiving oral corticosteroids & $22(24 \%)$ \\
\hline Total number of leukocytes in BAL $\mathrm{mm}^{-3}$ & $296 \pm 496$ \\
\hline \multicolumn{2}{|l|}{ Differential cell count } \\
\hline Macrophages \% & $46 \pm 31$ \\
\hline Eosinophils \% & $33 \pm 29$ \\
\hline Neutrophils \% & $15 \pm 24$ \\
\hline Lymphocytes \% & $8 \pm 10$ \\
\hline Mast cells \% & 0 \\
\hline \multicolumn{2}{|l|}{ Alveolar haemorrhage } \\
\hline Macroscopic bloody fluid & 0 \\
\hline Siderophages $>20 \%$ or GOLDE score $>100$ & $2 \pm 9$ \\
\hline
\end{tabular}

Data are presented as mean \pm SD or $\mathrm{n}(\%)$, unless otherwise stated. BAL: bronchoalveolar lavage. 

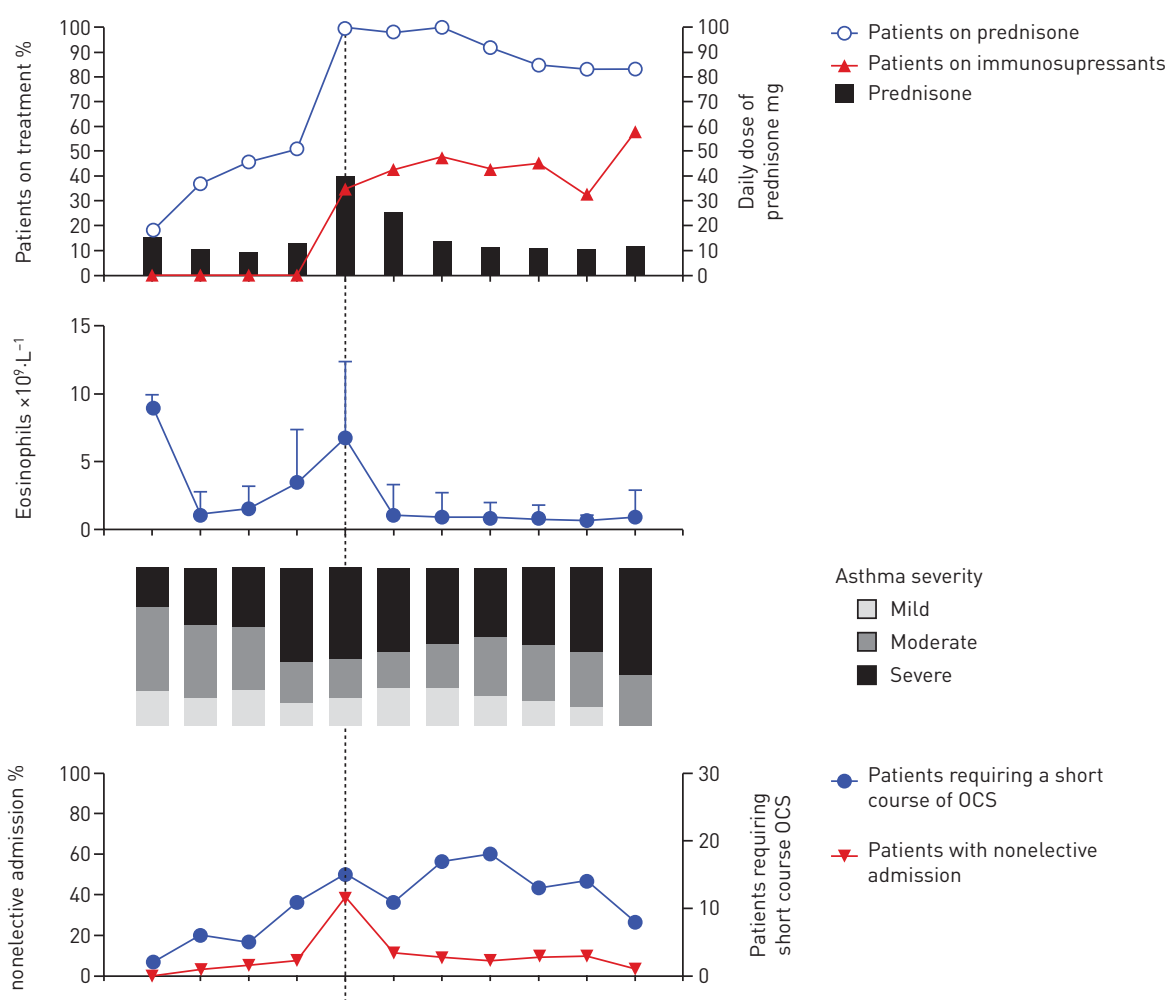

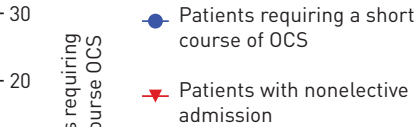

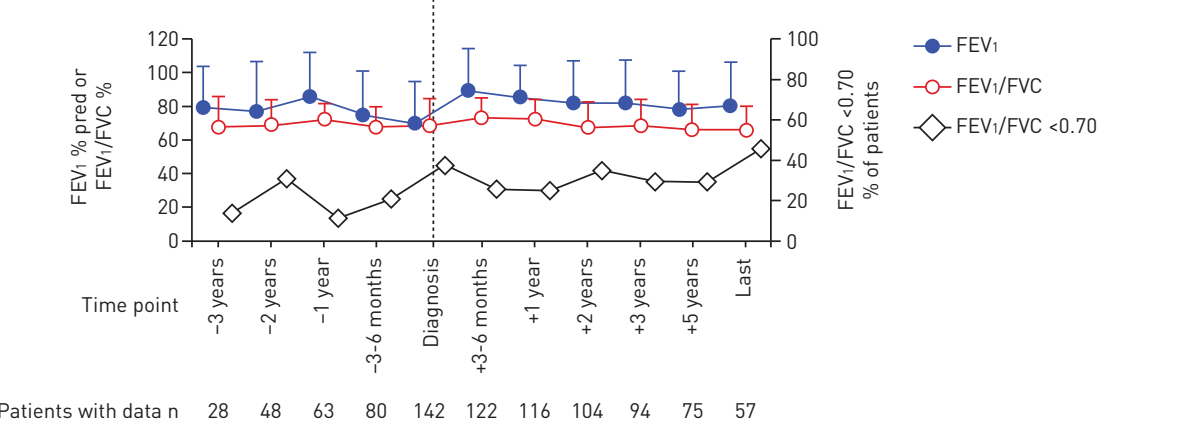

FIGURE 1 Time course of peripheral eosinophil count, asthma severity and lung function, with regard to oral corticosteroids (OCS) and immunosuppressive therapy in patients with eosinophilic granulomatosis with polyangiitis before and after the diagnosis. FEV1: forced expiratory volume in $1 \mathrm{~s}$; FVC: forced vital capacity.

The severity of asthma increased 3-6 months before the onset of the systemic manifestations, with one-third of patients having long-term airflow obstruction and severe asthma despite continuation of high-dose inhaled corticosteroids in all patients and oral corticosteroid treatment in more than $80 \%$ of patients. Only a quarter of the patients had a definite history of respiratory allergy. ENT manifestations predominantly consisted of non-allergic chronic rhinosinusitis, with nasal polyposis in half of the patients. CT features were variegated, with an indeterminate airspace/airway pattern in nearly half of cases.

Previous studies on EGPA either did not focus on respiratory manifestations [7, 8, 10, 23-26], or were limited in sample size $[6,9,27]$. The present study is a large, collaborative, multicentre study, with a mean \pm sD follow-up of $7.4 \pm 6.4$ years from the diagnosis of EGPA. As the investigators were mostly from respiratory medicine departments, the pulmonary features may have been overemphasised. We found a longer history of asthma before the onset of vasculitis when compared with the 3-6 (and up to 9) years found in previous studies [7]. Our data confirm that asthma frequently becomes severe and rapidly corticosteroid-dependent in the months before the onset of the vasculitis [6]. The asthma remained generally severe when the vasculitis flourished and once the vasculitis receded, in contrast to a previous report describing a favourable course of asthma over a shorter follow-up period of 2 years [27]. In a previous study of 24 consecutive patients with EGPA [9], we observed that $70 \%$ of patients had airflow obstruction at diagnosis, and five out of 13 patients with more than 3 years of follow-up had persistent airflow obstruction. Interestingly, a transient sustained increase in the daily dose of oral corticosteroids frequently improved 
TABLE 6 Treatment and outcome in 157 patients with eosinophilic granulomatosis with polyangiitis

\begin{tabular}{|c|c|}
\hline Mean $\pm s D$ (range) duration of follow-up years & $7.4 \pm 6.4(0-38.0)$ \\
\hline \multicolumn{2}{|l|}{ First-line systemic therapy } \\
\hline Systemic corticosteroids & $157(100 \%)$ \\
\hline Cyclophosphamide & $53(34 \%)$ \\
\hline Azathioprine & $13(8 \%)$ \\
\hline Methotrexate & $2(1 \%)$ \\
\hline Plasma exchange & $2(1 \%)$ \\
\hline Intravenous immunoglobulins & $1(1 \%)$ \\
\hline Deaths & $4(3 \%)$ \\
\hline \multicolumn{2}{|l|}{ Relapses } \\
\hline Number of patients with relapse & 78 (50\%) \\
\hline Patients with $1 / 2 / 3 / \geqslant 4$ relapses & $31 / 17 / 13 / 17$ \\
\hline \multicolumn{2}{|l|}{ Number of relapses } \\
\hline Total & 196 \\
\hline Mean \pm SD number of relapses per patient & $1.3 \pm 2.0$ \\
\hline Peripheral blood eosinophils $>0.5 \times 10^{9} \mathrm{~L}^{-1}$ & $139(71 \%)$ \\
\hline Peripheral blood eosinophil count $\times 10^{9} \mathrm{~L}^{-1}$ & $1.0 \pm 0.7$ \\
\hline \multicolumn{2}{|l|}{ Type of relapse } \\
\hline Asthma symptoms & $121(62 \%)$ \\
\hline Systemic manifestations & $72(37 \%)$ \\
\hline Pulmonary infiltrates (other than alveolar haemorrhage) & $9(5 \%)$ \\
\hline \multicolumn{2}{|l|}{ Treatment for relapse } \\
\hline Corticosteroids & $78(100 \%)$ \\
\hline Cyclophosphamide & $21(27 \%)$ \\
\hline Azathioprine & $22(28 \%)$ \\
\hline Methotrexate & $11(14 \%)$ \\
\hline Mycophenolate mofetil & $6(8 \%)$ \\
\hline Rituximab & $3(4 \%)$ \\
\hline Intravenous immunoglobulins & $3(4 \%)$ \\
\hline Omalizumab & $6(8 \%)$ \\
\hline Imatinib & $2(3 \%)$ \\
\hline Hydroxyurea & $2(3 \%)$ \\
\hline No other systemic therapy required & $20(26 \%)$ \\
\hline Not available & $10(13 \%)$ \\
\hline Long-term sequelae & $43(27 \%)$ \\
\hline Peripheral nerve involvement (or damage) & $14(9 \%)^{\#}$ \\
\hline Chronic left heart failure (left ventricular ejection fraction $<50 \%$ ) & $15(9 \%)^{\pi}$ \\
\hline Debilitating persistent chronic asthma & $13(8 \%)$ \\
\hline Corticosteroid related side-effects (diabetes, symptomatic osteoporosis, etc.) & $4(3 \%)$ \\
\hline Chronic renal insufficiency & $4(3 \%)$ \\
\hline Chronic debilitating fatigue & $1(1 \%)$ \\
\hline Chronic debilitating rhinosinusitis & $1(1 \%)$ \\
\hline
\end{tabular}

airflow obstruction and partially restored response to immediate inhaled beta-2-agonists [9]. In another series of 21 patients with adult-onset asthma and EGPA, asthma was severe in $68 \%$ of patients; however, asthma severity/control and lung function tests improved after initiating the treatment of vasculitis, and achieving stable remission of extra-respiratory manifestations [27]. In the present study, the mean FEV1 was $86.1 \pm 25.7 \%$ predicted 1 year before the diagnosis of EGPA, and only $69.7 \pm 24.9 \%$ predicted at the time of diagnosis (142 patients). With oral corticosteroids initiated at diagnosis of EGPA (together with continued inhaled corticosteroids and bronchodilators, and immunosuppressants in $43 \%$ of patients), FEV1 improved to $89.1 \pm 24.9 \%$ predicted 3-6 months after diagnosis, and was $78.1 \pm 22.8 \% 5$ years after diagnosis in the 75 patients who were still followed in respiratory departments. Furthermore, $46 \%$ of patients had FEV $1 / \mathrm{FVC}$ $<0.7$ and $\mathrm{FEV}_{1}<80 \%$ predicted at the last follow-up. Although the available data may have been influenced by the persistence of symptoms, because patients with persistent airflow obstruction are more likely to be followed in respiratory departments over the long term, our findings nevertheless confirm that persistent airflow obstruction is present in the long term in a significant proportion of patients, and contributes to morbidity in EGPA. Our data compare with the study by SAMSON et al. [20], in which $83 \%$ of patients with 
EGPA still suffered from chronic asthma at the final visit. Due to the study design, other contributors to morbidity, and especially treatment-induced adverse events, could not be evaluated precisely.

This study confirms the high frequency of ENT manifestations in patients with EGPA, with three-quarters of patients having chronic rhinosinusitis, and half having nasal polyposis. Furthermore, ENT manifestations significantly contributed to morbidity, because more than half of cases with nasal polyposis had a complicated course requiring surgery, with relapses in $28 \%$ of cases, and hearing loss due to chronic otitis media. This is comparable to previous results in several series [6, 10, 27-29].

The prevalence of allergy was low in patients with EGPA, as reported by BotTero et al. [30]. Chronic rhinosinusitis was of non-allergic type in a majority of cases, with the presence of chronic maxillary rhinosinusitis or nasal polyposis rich in eosinophils. A definite history of respiratory allergy was found in only a quarter of patients. When present, asthma and rhinitis symptoms were perennial in most cases.

Recently, CT bronchopulmonary features of EGPA have been tentatively categorised into an airway pattern (with most patients having an obstructive or mixed obstructive and restrictive ventilatory defect), and an airspace pattern [17]. Imaging features in our study could not be categorised in about half the cases, thus limiting radiological functional correlations, and illustrating that fine analysis in detailed radiological studies may be difficult to implement in larger populations of patients. Direct features of bronchiolitis were infrequent, with centrilobular nodules, branching opacities, tree-in-bud pattern and mosaic attenuation found in $14 \%, 12 \%, 10 \%$ and $4 \%$ of cases, respectively, suggesting that some may fit the definition of the recently described entity of hypereosinophilic obliterative bronchiolitis with the notable exception of systemic manifestations that define EGPA [31]. Pulmonary fibrosis [32] was not observed in this series.

Because there are currently no established diagnostic criteria for EGPA, the inclusion criteria reflected common practice in specialised centres, realistically selecting patients who share common disease features and outcome. All had a history of asthma, eosinophilia and at least one systemic organ manifestation (other than asthma, pulmonary or ENT involvement) directly attributable to EGPA. LANHAM et al. [7] have proposed three diagnostic criteria including: 1) asthma, 2) eosinophilia exceeding $1.5 \times 10^{9} \mathrm{~L}$, and 3) systemic vasculitis of two or more extrapulmonary organs. However, these criteria do not include ANCAs (not available at that point in time), which, when present, contribute to the diagnosis. Classification criteria proposed by the American College of Rheumatology [22] only contribute to diagnosis in an individual with suspected EGPA and established systemic vasculitis. However, a pathological diagnosis of vasculitis is seldom obtained in patients with characteristic features of EGPA. Provisional diagnostic criteria including ANCA have been recently proposed [2] and are currently being evaluated.

One pitfall of the new definition of EGPA [1] is that not all patients with EGPA may have definite criteria of polyangiitis; therefore questioning the validity of the terminology of EGPA [2]. Only 64 patients in our series had definite features of vasculitis. In addition, 42 patients in the series had a single extrathoracic manifestation, including 30 with a single feature of definite vasculitis. This finding supports the notion that the definition by LANHAM et al. [7] and the EGPA terminology do not apply well to patients from respiratory medicine departments $[2,27]$.

Limitations of this study include its retrospective design; however, this is unlikely to have affected the results especially the minimal estimated frequency and type of respiratory and systemic manifestations. The physicians involved in this study have a strong interest in EGPA and routinely recorded extensive patient files, and most cases were prospectively collected in institutional databases. All consecutive patients evaluated in all participating groups over the study period were included. Estimates of the proportion of patients with severe asthma or persistent airflow obstruction are consistent with our prior smaller study [9]. Evaluation of the severity and control of asthma may lack accuracy, as no formal assessment was conducted prospectively; however, the criteria used (including frequency of nonelective hospitalisation and requirement for short-term oral corticosteroids) are robust. Imaging features were not centrally reviewed, which may have limited categorising airway and airspace patterns of disease. Not all patients had pulmonary function data prior to the diagnosis of EGPA. Although not all patients had long-term follow-up with pulmonary function tests available for review, the data presented clearly demonstrate that persistent airflow obstruction contributes to morbidity in a significant proportion of patients with EGPA. Whether treatment with an anti-interleukin-5 monoclonal antibody may improve lung function remains to be evaluated.

In conclusion, this large study of respiratory manifestations in EGPA demonstrates that asthma antedates the onset of the systemic manifestations by a mean of 12 years, with an increase in the severity of asthma 3-6 months before the onset of the systemic manifestations, and shows that one-third of patients develop long-term fixed airflow obstruction despite inhaled and often oral corticosteroid treatment. These findings are relevant for the long-term management of patients with EGPA. 


\section{Acknowledgements}

We are grateful to Anne Beghoul, Raphaele Guelminger, Marion Durand, Chantal Silarakis, Sabrina Zeghmar (all at the National reference center for rare pulmonary diseases, Lyon, France) who contributed to data acquisition and entry.

Groupe d'Etudes et de Recherche sur les Maladies Orphelines Pulmonaires (GERM“O”P) members that contributed to the study were as follows: Guillaume Beltramo (Dijon, France), Pascal Beynel (Bourg en Bresse, France), Isabelle Court-Fortune (Saint-Etienne, France), Emmanuel Gomez (Nancy, France), Lize Kiakouama (Lyon, France), Christophe Leroyer (Brest, France), Marianne Levesque (Montréal, Canada), Anita Mollard (Strasbourg, France), Christophe Rogé (Morlaix, France). Other members of the core panel: Wolfgang Gross, Peter A. Merkel, Ulrich Specks, Jean Bousquet, Eric Marchand, Ian Pavord, Johan-Christian Virchow.

Members of the European Respiratory Society Taskforce on eosinophilic granulomatosis with polyangiitis (Churg-Strauss) were as follows. Chairs: Loïc Guillevin (Paris, France), J.F. Cordier (Lyon, France), David Jayne (Cambridge, UK). Secretary: Christian Pagnoux (Toronto, Canada). Associated secretaries: Vincent Cottin (Lyon, France) for the respiratory panel and Matthieu Groh (Paris, France) for the vasculitis panel. Core panel: Wolfgang L. Gross (Lübeck and Bad Bramstedt, Germany), Peter A. Merkel (Philadelphia, USA), Renato A. Sinico (Milan, Italy), Ulrich Specks (Rochester, MN, USA) and the chairs, secretary and associated secretaries. Vasculitis panel: Chiara Baldini (Pisa, Italy), Paolo Bottero (Milan, Italy), Bertrand Dunogué (Paris, France), Matthieu Groh (Paris, France) (Chair of the vasculitis task force), Wolfgang Gross (Lübeck and Bad Bramstedt, Germany), Loïc Guillevin (Paris, France) (Chair of the vasculitis task force), Julia Holle (Lübeck and Bad Bramstedt, Germany), David Jayne (Cambridge, UK), Charles Jennette (Chapel Hill, North Carolina, USA), Alfred Mahr (Paris, France), Peter A. Merkel (Philadelphia, Pennsylvania, USA), Luc Mouthon (Paris, France), Christian Pagnoux (Toronto, Canada), Renato A. Sinico (Milano, Italy), Ulrich Specks (Rochester, Minnesota, USA), Augusto Vaglio (Parma, Italy). Respiratory consultant panel: Elisabeth Bel (Amsterdam, Netherlands), Jean Bousquet (Montpellier, France), Jean-François Cordier (Lyon, France) (Chair of the ERS task force), Vincent Cottin (Lyon, France) (Secretary of the ERS task force), Klaus Dalhoff (Lübeck, Germany), Marc Humbert (Paris, France), Romain Lazor (Lausanne, Switzerland), Eric Marchand (Yvoir, Belgique), Pasupathy Sivasothy (Cambridge, UK), Ulrich Specks (Rochester, USA) (Core panel ERS task force), Johan-Christian Virchow (Rostock, Germany), Michael E. Wechsler (Denver, USA).

\section{References}

1 Jennette JC, Falk RJ, Bacon PA, et al. 2012 revised International Chapel Hill Consensus Conference Nomenclature of Vasculitides. Arthritis Rheum 2013; 65: 1-11.

2 Cordier JF, Cottin V, Guillevin L, et al. L5. Eosinophilic granulomatosis with polyangiitis (Churg-Strauss). Presse Med 2013; 42: 507-510.

3 Cottin V, Cordier JF. Eosinophilic pneumonia. In: Mason RJ, Ernst JD, King TE Jr, et al., eds. Murray and Nadel's Textbook of Respiratory Medicine. 6th Edn. Philadelphia, Elsevier Saunders, 2016; pp. 1221-1242.

4 Mahr A, Moosig F, Neumann T, et al. Eosinophilic granulomatosis with polyangiitis (Churg-Strauss): evolutions in classification, etiopathogenesis, assessment and management. Curr Opin Rheumatol 2014; 26: 16-23.

5 Jennette JC, Falk RJ, Andrassy K, et al. Nomenclature of systemic vasculitides. Proposal of an international consensus conference. Arthritis Rheum 1994; 37: 187-192.

6 Tsurikisawa N, Tsuburai T, Saito H, et al. A retrospective study of bronchial hyperresponsiveness in patients with asthma before the onset of Churg-Strauss syndrome. Allergy Asthma Proc 2007; 28: 336-343.

7 Lanham JG, Elkon KB, Pusey CD, et al. Systemic vasculitis with asthma and eosinophilia: a clinical approach to the Churg-Strauss syndrome. Medicine (Baltimore) 1984; 63: 65-81.

8 Guillevin L, Cohen P, Gayraud M, et al. Churg-Strauss syndrome. Clinical study and long-term follow-up of 96 patients. Medicine (Baltimore) 1999; 78: 26-37.

9 Cottin V, Khouatra C, Dubost R, et al. Persistent airflow obstruction in asthma of patients with Churg-Strauss syndrome and long-term follow-up. Allergy 2009; 64: 589-595.

10 Comarmond C, Pagnoux C, Khellaf M, et al. Eosinophilic granulomatosis with polyangiitis (Churg-Strauss): clinical characteristics and long-term followup of the 383 patients enrolled in the French Vasculitis Study Group cohort. Arthritis Rheum 2013; 65: 270-281.

11 Guillevin L, Lhote F, Gayraud M, et al. Prognostic factors in polyarteritis nodosa and Churg-Strauss syndrome. A prospective study in 342 patients. Medicine (Baltimore) 1996; 75: 17-28.

12 Watts R, Lane S, Hanslik T, et al. Development and validation of a consensus methodology for the classification of the ANCA-associated vasculitides and polyarteritis nodosa for epidemiological studies. Ann Rheum Dis 2007; 66: 222-227.

13 Fokkens W, Lund V, Bachert C, et al. EAACI position paper on rhinosinusitis and nasal polyps executive summary. Allergy 2005; 60: 583-601.

14 Miller MR, Hankinson J, Brusasco V, et al. Standardisation of spirometry. Eur Respir J 2005; 26: 319-338.

15 Chung KF, Wenzel SE, Brozek JL, et al. International ERS/ATS guidelines on definition, evaluation and treatment of severe asthma. Eur Respir J 2014; 43: 343-373.

16 Reddel HK, Bateman ED, Becker A, et al. A summary of the new GINA strategy: a roadmap to asthma control. Eur Respir J 2015; 46: 622-639.

17 Kim YK, Lee KS, Chung MP, et al. Pulmonary involvement in Churg-Strauss syndrome: an analysis of CT, clinical, and pathologic findings. Eur Radiol 2007; 17: 3157-3165.

18 Guillevin L, Pagnoux C, Seror R, et al. The Five-Factor Score revisited: assessment of prognoses of systemic necrotizing vasculitides based on the French Vasculitis Study Group (FVSG) cohort. Medicine (Baltimore) 2011; 90: 19-27.

19 Groh M, Pagnoux C, Baldini C, et al. Eosinophilic granulomatosis with polyangiitis (Churg-Strauss) (EGPA) Consensus Task Force recommendations for evaluation and management. Eur J Intern Med 2015; 26: 545-553.

20 Samson M, Puechal X, Devilliers H, et al. Long-term outcomes of 118 patients with eosinophilic granulomatosis with polyangiitis (Churg-Strauss syndrome) enrolled in two prospective trials. J Autoimmun 2013; 43: 60-69.

21 Cordier JF, Cottin V. Eosinophilic pneumonias. In: Schwarz MI, King TE Jr, eds. Interstitial Lung Disease. 5th Edn. Shelton, People’s Medical Publishing House-USA, 2011; pp. 833-893. 
22 Masi AT, Hunder GG, Lie JT, et al. The American College of Rheumatology 1990 criteria for the classification of Churg-Strauss syndrome (allergic granulomatosis and angiitis). Arthritis Rheum 1990; 33: 1094-1100.

23 Chumbley LC, Harrison EG Jr, DeRemee RA. Allergic granulomatosis and angiitis (Churg-Strauss syndrome). Report and analysis of 30 cases. Mayo Clin Proc 1977; 52: 477-484.

24 Sablé-Fourtassou R, Cohen $\mathrm{P}$, Mahr A, et al. Antineutrophil cytoplasmic antibodies and the Churg-Strauss syndrome. Ann Intern Med 2005; 143: 632-638.

25 Sinico RA, Di Toma L, Maggiore U, et al. Prevalence and clinical significance of antineutrophil cytoplasmic antibodies in Churg-Strauss syndrome. Arthritis Rheum 2005; 52: 2926-2935.

26 Healy B, Bibby S, Steele R, et al. Antineutrophil cytoplasmic autoantibodies and myeloperoxidase autoantibodies in clinical expression of Churg-Strauss syndrome. J Allergy Clin Immunol 2013; 131: 571-576.

27 Szczeklik W, Sokolowska BM, Zuk J, et al. The course of asthma in Churg-Strauss syndrome. J Asthma 2011; 48: 183-187.

28 Bacciu A, Bacciu S, Mercante G, et al. Ear, nose and throat manifestations of Churg-Strauss syndrome. Acta Otolaryngol 2006; 126: 503-509.

29 Bacciu A, Buzio C, Giordano D, et al. Nasal polyposis in Churg-Strauss syndrome. Laryngoscope 2008; 118: 325-329.

30 Bottero P, Bonini M, Vecchio F, et al. The common allergens in the Churg-Strauss syndrome. Allergy 2007; 62: $1288-1294$.

31 Cordier JF, Cottin V, Khouatra C, et al. Hypereosinophilic obliterative bronchiolitis: a distinct, unrecognised syndrome. Eur Respir J 2013; 41: 1126-1134.

32 Comarmond C, Crestani B, Tazi A, et al. Pulmonary fibrosis in antineutrophil cytoplasmic antibodies (ANCA)-associated vasculitis: a series of 49 patients and review of the literature. Medicine (Baltimore) 2014; 93: 340-349. 